\title{
Semantic and phonetic memory codes in beginning readers
}

\author{
BRIAN BYRNE and PETER SHEA \\ University of New England, Armidale, 2351 Australia
}

\begin{abstract}
In two experiments a group $(N=15)$ of poor beginning readers and of good readers $(N=15)$ were auditorily presented with continuous item lists. The children were asked to indicate whether each item had occurred previously in the list. In Experiment 1, using real words, later items were related either semantically or as rhymes to earlier ones. False positives to each item type were taken as indices of memory coding and showed that good readers encoded both semantic and surface aspects of items. In contrast, poor readers made a large number of meaning-based confusions (saying "old" to house when home had been presented earlier) but almost none based on rhyme (home/comb confusions). In a second experiment, with phonetically legal nonwords as items, poor readers made a significant number of phonetic false positives, although the good reader controls made more. The results are interpreted as confirming that poor readers are relatively insensitive to surface features of language but that this weakness is most marked when sound and meaning are both available as memory codes.
\end{abstract}

The research reported in this paper addresses the question of how young retarded readers code words and pseudowords in a memory task. The work was motivated by two sets of considerations: first, the accumulating evidence that poor readers show only a weak active awareness of the structure of the speech code and, second, arguments concerning the primacy of meaning over form in preliterate children's reaction to language. These latter ideas will be explored more fully following Experiment 1.

There is now considerable evidence which indicates that preliterate children, and those who are experiencing difficulty in learning to read, perform poorly on word games that require them to manipulate aspects of the sounds of words. For example, Firth (1972) discovered that 8-year-old backward readers were much worse than an intelligence-matched group of average readers in eliding segments from orally presented words-in saying, for instance, what is left when /f/ is taken from/f ae $n /$ (see also Bruce, 1964). In an unpublished study from our laboratory, Arnold (Note 1) confirmed Firth's findings with phoneme elision and extended the investigation to elision of syllabic segments from words (e.g., /llmIt/ minus / IIm/). Poor readers were also weaker at this task. Rozin and Gleitman (1977) have reviewed much of the available data on word segmentation and combination skills in retarded readers; they found consistently that these subjects were poorer than comparable coping readers.

Difficulties in operating with the speech code are not

This paper is based on a BA honors thesis by P.S. The authors are grateful to the staff and students of Armidale Public School for their cooperation. Request reprints from the first author, Department of Psychology, University of New England, Armidale, N.S.W. 2351, Australia. restricted to the active identification and manipulation of word segments. Poor readers apparently have a diminished ability to use phonetic recoding strategies in a variety of memorization tasks. For example, Shankweiler and Liberman (1976) showed that introducing acoustic confusability into to-be-memorized letter strings adversely affected performance of superior readers more than that of marginal and poor ones. This was true with both immediate and delayed recall and with visually or auditorily presented strings. In a similar vein, Mark, Shankweiler, Liberman, and Fowler (1977) found that the false-positive errors of good readers in a word recognition test were considerably greater in number when the foils rhymed with the initial stimulus words than when they did not, but the rhyme/nonrhyme variable had little effect on error rates of poor readers. In that experiment, the subjects were required to read the words. In the work reported in this paper, good and poor readers were given a continuous word recognition test, similar to that devised by Felzen and Anisfeld (1970), in which the items were presented auditorily. The children were required to indicate whether each word had previously appeared on the list. The false-positive error rate to rhyming foils served as a check on the generality of the results of the Mark et al. (1977) study, using auditory presentation and a different recognition task. It was expected that poor readers would make fewer such errors than good readers because of their apparently diminished ability to code phonetic features.

In Experiment 1 some of the words were semantically related, as synonyms or antonyms, to earlier presented items. These acted as something of a control for possible differences in general memory capacity between good and poor readers. The expectation was that poor readers would exhibit a strong reliance on the semantic code, in 
the absence of competition from the speech code, and that this would show up as a relatively high rate of false positives for these items. If that pattern of results occurred, it would again suggest the atypicality of retarded readers, since it has generally been found that children around the age of our subjects tend to make more phonetic- than semantic-based errors.

\section{EXPERIMENT 1}

\section{Method}

Subjects. All subjects were second-grade children attending Armidale Public School. The poor readers were defined as being 1 year or more behind in reading age, relative to chronological age, on a standardized reading test. The St. Lucia Word Reading Test (Andrews, Note 2) was used. There were 15 children in this group, 11 boys and 4 girls, with a mean reading age of $5: 11$ and a chronological age of $7: 6$. The 15 coping readers ( 8 boys, 7 girls) had reading and chronological ages of $8: 7$ and 7:5, respectively. The poor and good readers were also widely separated on a nonsense-word reading test, devised by Firth (1972), who found it to be the best single predictor of word reading ability. The test consists of 170 nonwords, such as $a b$ and ither, which subjects are required to pronounce. The poor readers scored an average of 63 correct, with a range of 21-117. All of the control subjects successfully read to the end of the test; the largest number of mispronunciations of a single subject was 12 .

The mean IQ of the backward readers, as assessed by the Slosson Intelligence Test (Slosson, Note 3), was 115, not significantly different from the good readers' mean of 118 .

Materials and Procedure. The word list for the experiment centered on 12 clusters, each of five words. Each antecedent (A) word was coupled with a semantically related word ( $\mathrm{S}$, a synonym or antonym) and a rhyming word (R). For each $S$ and $R$ word there was a control word (CS and CR), and, in all but a few instances, the control words matched their experimental partners ( $S$ and $R$ words) in part of speech, syllabic length, and ThorndikeLorge (1944) frequency rating. The selected $R$ words were orthographically dissimilar to their A counterparts. This was done to avoid, as far as possible, offering the good readers a source of confusability, visualized spelling pattem, that the poor readers may not have had available. These 12 clusters are presented in Table 1.

In the list each $A$ word appeared twice, the second presentation following the first by eight positions. Each experimental and each control word appeared only once, and experimentalcontrol pairs were separated by one item. In half of these cases the experimental word preceded its control; the arrangement

Table 1

The Antecedent, Experimental, and Control Words Used in Experiment 1

\begin{tabular}{llllll}
\hline \multirow{2}{*}{$\begin{array}{c}\text { Antecedent } \\
\text { Word }\end{array}$} & \multicolumn{2}{c}{ Semantic } & & \multicolumn{2}{c}{ Rhyming } \\
\cline { 2 - 3 } \cline { 5 - 6 } home & hoution & Control & & Relation & Control \\
\hline city & town & ship & comb & glove \\
carpet & rug & soup & pretty & zebra \\
thief & crook & tag & leaf & army \\
gun & rifle & bubble & done & ripe \\
cold & freezing & cheerful & rolled & use \\
slow & fast & next & toe & hang \\
high & low & first & my & her \\
white & black & round & right & best \\
go & come & keep & row & feed \\
sweet & sour & plump & heat & bird \\
take & give & kill & ache & help \\
\hline
\end{tabular}

was reversed for the other pairs. The experimental and control words always came after the second appearance of the appropriate A words, following them by 9 or 14 places. On half the occasions an $S$ word occupied Position 9 after the $A$ word, with $R$ words on the other half. The same arrangement held for Positon 14 (six $\mathrm{S}$ words and six $\mathrm{R}$ words).

The 12 clusters provided 72 items, including the repetition of each $A$ word. In all, there were 121 words in the list, the rest being filler items that bore no obvious relation to the other words. Of the 28 words used as fillers, 10 appeared once, 15 twice, and 3 three times. They occupied Positions 1-5, 7, 8, $10-13,15,16,18$, and 20 , with the remaining 34 positioned in spaces throughout the list after location of $A, S, R, C S$, and $C R$ items.

The list was recorded on reel-to-reel tape and played on a Sony TC-105. Each $5.5 \mathrm{sec}$ (see Felzen \& Anisfeld, 1970) a warning signal occurred, followed by a word. The children were told to say "new" after any word they had not heard before on the tape and "old" after any item that had occurred previously. Practice was given prior to the test, using words unrelated to those in the main list. The subjects' responses were recorded for later transcription and analysis. Each child was tested individually in the school clinic.

\section{Results and Discussion}

Two kinds of errors could be made in the experiment: saying "new" to old words and "old" to ones that had not been previously presented. The percentage of errors on all 121 words was 12.9 for good readers and 13.4 for poor readers. The difference was not significant $[\mathrm{t}(28)=.27, \mathrm{p}>.40]$. The mean number of false positives to experimental, control, and filler words (i.e., saying "old" upon the first presentation of any item) was 9.7 for good readers and 6.7 for poor. The difference was not significant $[t(28)=1.29$, $\mathrm{p}>.20$ ] and was largely due to the particularly high error rate (32) of a single good reader. Poor readers made more false negatives (saying "new" to any item on its second or third presentation) than did the coping readers; respective means were 9.5 and $5.9[\mathrm{t}(28)=$ $3.019, \mathrm{p}<.01]$.

The main interest centers upon false positives to experimental and control words, saying "old" to words that had not previously appeared. The data are presented in Table 2. For each subject the differences between rhyming foils ( $R$ words) and their controls (CR), and between semantic foils (S) and their controls (CS), were calculated and subjected to an analysis of variance.

There was a significant interaction $[F(1,23)=12.87$, $\mathrm{p}<.01]$ as well as a significant main effect for item type (semantic vs. rhyming) $[\mathrm{F}(1,28)=8.13, \mathrm{p}<.01]$, but no between-subject effect $[F(1,28)=.04]$. Most of the interaction rests upon a particularly low R-RC score for poor readers. In fact, the near-zero mean indicates that these children did not rely sufficiently upon the phonetic code for it to be a source of confusion in recognition. On the other hand, there is ample evidence of coding in terms of meaning, so much that poor and good readers could not be distinguished in false-positive error rates collapsed over semantic and rhyming items. The relevant means are 2.5 for poor 
Table 2

Mean Number of False Positives to Experimental and Control Words: Experiment 1

\begin{tabular}{lcc} 
& \multicolumn{2}{c}{ Relations } \\
\cline { 2 - 3 } & \multicolumn{2}{c}{ Poor Readers } \\
& 3.07 & .67 \\
Experimental & .67 & .60 \\
Control & 2.40 & .07 \\
Difference & \multicolumn{2}{c}{ Good Readers } \\
Experimental & 2.07 & 2.80 \\
Control & .73 & 1.40 \\
Difference & 1.34 & 1.40 \\
\hline
\end{tabular}

readers and 2.7 for good readers. Separate two-tailed $t$ tests on the mean difference in Table 2 showed that poor readers made significantly fewer rhyme-based errors than did good readers $[\mathrm{t}(28)=3.18, \mathrm{p}<.01]$ and that the poor readers' score of 2.40 on semantic errors was almost significantly higher than the good readers' $1.34[\mathrm{t}(28)=1.78, \mathrm{p}<.10]$. In addition, each of the four mean differences was significantly above zero, except that for poor readers' rhyming relations. The good readers in this experiment produced the same pattern of results as the young children studied by Felzen and Anisfeld (1970) and Frumkin and Anisfeld (1977), that is, more errors based on phonetic similarity than semantic overlap. The effect was not as marked in these subjects as in those Anisfeld and his co-workers reported, however.

This group of poor readers, like those in others' studies, showed insensitivity to the surface code in spoken language. Such demonstrations are useful in that they complement the finding that reading skill and conscious manipulation of speech elements are correlated. What is not clear, of course, is what lies behind the phenomenon. It could be reading instruction itself. There is ample evidence that learning to read carries along with it insights into aspects of the structure of language (Ehri, 1975; Francis, 1973). Thus, failure to profit from lessons in reading may leave children relatively unenlightened about phonological structure. On the other hand, it may be that easy mastery of the process of reading demands some minimal insight into the structure of the sound stream (Rozin \& Gleitman, 1977), and there may exist a minority of children who do not reach this level of understanding as quickly as does the majority. These therefore become the retarded readers. This chicken-and-egg question requires further study, possibly in the form of a training program aimed at inducing an appropriate level of phonological awareness in the early stages of exposure to reading instruction (see Williams, 1977). The effects, if any, on the course of reading acquisition would be instructive. For the present, however, we simply assume that thinking about, or in terms of, the sounds of language does not come naturally to young children, and explore one possible reason for this assumption in Experiment 2.

\section{EXPERIMENT 2}

The emphasis in recent theorizing about phonological awareness and its development has been upon the complicated structure of the speech signal and the consequent difficulties in being explicitly aware of its make-up (e.g., Liberman, Shankweiler, Fischer, \& Carter, 1974; Liberman, Shankweiler, Liberman, Fowler, \& Fischer, 1977; Rozin \& Gleitman, 1977; Shankweiler \& Liberman, 1976). Phonetic segments overlap within the signal, so in many cases the exact nature of phonetic forms are dependent on their acoustic environments. This applies to a greater extent to phonemes than to syllables and to consonants more than to vowels. Yet there are reasons for being unsure of how adequately this set of facts accounts for the present results and others like it. First, as mentioned above, vowels retain their integrity within the sound stream more than do consonants, and it was rhyme, a vowel-based property of word pairs, that provided the phonetic similarity in this experiment. Second, it is not obvious that features which inhibit the conscious identification of the elements of the speech stream should also block encoding of words as sounds in a memory task. As authors frequently point out, children who fail to segment words correctly nevertheless clearly know what the word is (e.g., can distinguish it from another which shares all but one phonetic feature) and can say it. Why, then, do they not remember it as a sound? Should a structural analysis of the speech signal be any more necessary for using the speech signal as a mnemonic device than it is for distinguishing it or producing it? It may be, but this proposition does not follow in a compelling manner from the evidence.

A rather different perspective on access to surface levels of language is afforded by the idea that, for the child, form and meaning in language are intimately bound. Stern (1914/1971) is best known for the view that a thing's name becomes part of the thing. The relationship, Stern asserts, is two-way: "The thing itself gains from the fact that it can be named, an increase in stability and permanence, and the name from its firm anchorage in the structure of the thing takes on some touch of its physiognomy; it sounds as the thing looks or moves or feels to the touch-a species of sound painting which now appears side by side with the natural utterance" (1971, p. 47). Vygotsky (1962), while maintaining a distance from Stern's extreme stance, also emphasizes the intimate connection of form and meaning, especially in the context of written language, drained as it is of the motivational and interpersonal features that characterize dialogue. If there is substance to this kind of notion, it may well mean that focusing upon the form of a word, its sound, may run into stiff competition from the predominant reaction, to its 
meaning. One important lesson from cognitive psychology is that the brain is highly interpretive, whether we look at the intrusion of interpretation into quite peripheral levels of information processing (Erdelyi, 1974) or at aspects of longer term ideation (see Jenkins, 1974). Conceivably, there is another example of that general principle. Tasks which ask children to divorce form and meaning so as to analyze the physical signal, or give them the opportunity to use form as a memory code, invite them to move, in part, away from an important aspect of their linguistic experience, that names stand for things, and to treat the name itself as the object.

McNeil and Stone (1965) tested a hypothesis derived from the above reasoning, that kindergarten children would better be able to detect a designated phoneme in a nonsense word than in an actual word. They were proved correct. Thinking about the sounds that make up language is easier for children if the sounds mean nothing. Experiment 2 was aimed at discovering whether the continuous recognition task could detect phonemic encoding in our sample of poor readers if pseudowords were used.

\section{Method}

Subjects. The children who participated in Experiment 1 were tested in this study. They were tested 6 weeks after the initial experiment.

Material and Procedure. Twelve clusters of nonwords formed the basis of the item list. For each antecedent (A) item there was a rhyming foil (R) and a control nonword (C). The A items were closely related to the A words of Experiment 1 , usually being formed by changing the first phoneme to produce a meaningless word (e.g., home became jome). The R items were also meaningless (e.g., vome), and $\mathrm{C}$ items were mostly based on their counterparts in Experiment 1 . Natually, there were no semantically related items and controls. See Table 3 for the items.

The list was constructed along the same lines as those used for Experiment 1. Each A item appeared twice, separated by eight positions. The $R$ and $C$ items occurred next-but-one to each other, Rs being first half the time. Six of the $R$ items were placed nine positions after the second occurrence of their As, and the remaining six came after 14 intervening items. There were thus 48 positions based on the 12 clusters. In addition, 18 filler items, nonwords that did not rhyme with any other items, occupied the first five positions and appropriate other places throughout the list.

Table 3

The Antecedent, Experimental, and Control Items Used in Experiment 2

\begin{tabular}{lll}
\hline \multirow{2}{*}{$\begin{array}{c}\text { Antecedent } \\
\text { Item }\end{array}$} & \multicolumn{2}{c}{ Rhyming } \\
\cline { 2 - 3 } jome & Relation & Control \\
sheam & vome & fove \\
ko & feam & lipe \\
dake & vo & wang \\
hity & pake & jelp \\
kigh & fity & febra \\
geet & vigh & ter \\
corpot & reet & kird \\
pite & corput & larmy \\
lun & gite & kest \\
nold & mun & fut \\
lish & lold & puse \\
\hline
\end{tabular}

Table 4

Mean Number of False Positives to Experimental and Control Items: Experiment 2

\begin{tabular}{lcc}
\hline & \multicolumn{2}{c}{ Rhyming Relations } \\
\cline { 2 - 3 } & Poor Readers & Good Readers \\
\hline Experimental & 4.33 & 5.26 \\
Control & 2.40 & 1.53 \\
Difference & 1.93 & 3.73 \\
\hline
\end{tabular}

The list was recorded in the same fashion as in Experiment 1, with $5.5 \mathrm{sec}$ between waming tones. Instructions emphasized that what the children would hear "sounded like words, but weren't real words." Examples were given and practice ensured the instructions to say "new" and "old" were understood by each subject. Responses were recorded and later analyzed.

\section{Results and Discussion}

Good readers made errors on $19.1 \%$ of the items, poor readers on $22.0 \%[\mathrm{t}(28)=1.053, \mathrm{p}>.20]$. The two subject groups were also indistinguishable in terms of false negatives (good readers, 4.2 ; poor readers, 4.9 ) and total false positives ( 8.4 and 9.6 , respectively). The $t$ values for the respective comparisons were .68 and .52 .

The pattern of false positive error rates to experimental and control items is clear in Table 4. It is apparent that the poor readers made significantly more errors on the foils than on the control words $[t(14)=4.08$, $\mathrm{p}<.01]$. This result stands in contrast to that in Experiment 1, in which poor readers made no more false positives to $\mathrm{R}$ than to $\mathrm{RC}$ words. The good readers also made phonetic confusions and, in fact, the R-C difference for the good subjects was significantly higher than for the poor group $[\mathrm{t}(28)=2.13, \mathrm{p}<.05]$. It seems clear, therefore, that phonetic encoding of word-like sounds can occur to an extent that shows up as rhymebased confusion in this memory task among poor readers, although their sensitivity to the surface code is still weaker than that of children who can read adequately. It seems unlikely that the particular phoneme sequences making up the items of this experiment were physically more penetrable than those in Experiment 1, and hence we feel safe in attributing the difference to the lack of meaning of these items. Because the good readers made more recognition errors, however, meaningfulness cannot be the whole story. It is probably true that for some children speech is simply not as powerful a code for memorization as it is for other children. We suggest, however, that the "distraction" of meaning may mask at least some of the potency the speech code can have for poor readers.

We remain somewhat puzzled by the failure to find a significantly higher rate of false negatives among poor readers than good readers in this experiment. One might reasonably expect a relatively low rate of E-C false positives, taken to indicate weaker encoding, to go hand in hand with an increase in misses of previously presented items. Further research is needed to discover if 
we have a decision error here or whether the two indices do not in fact reflect the same process.

\section{GENERAL DISCUSSION}

The two experiments reported here provide another instance of poor readers' relatively weak access to the sounds of language as a memory code and suggest that this weakness is most marked when attention to sound and meaning are in competition. It appears that the phonetic code, which occupies a unique place in memory in most people, does not carry its usual load in young poor readers, and this state of affairs may, in part, exist because of these subjects' difficulty in divorcing form and meaning in speech.

We have argued in favor of a qualitative difference in encoding strategy between coping and backward young readers. The threat to this kind of reasoning is the general capacity argument, that poor readers are doing essentially the same thing as their superior counterparts, but less effectively. The central reason for doubting the capacity position in these experiments is the interaction effect in Experiment 1. Apparently the type of overlap, semantic or phonetic, between experimental items and foils determines relative error rates and not simply subject type. The capacity argument predicts the same pattern of errors for poor readers as good, but on a smaller scale, the semantic and surface features of the words being less firmly encoded. On the other hand, the higher number of false negative errors committed by the weaker children is consistent with lowered general processing capacity; they were less able to recognize previously presented items. But this result may also fit a strategy-difference explanation if it is assumed that having two codes, meaning and form, available for encoding leads to better storage than does relying primarily on one (meaning, in the case of poor readers). One might embellish the processing capacity argument by combining it with an admission that meaning is the first aspect of stimuli to be encoded in this memory task and that poor readers have little residual to store surface elements except when meaning is absent. This, however, seems to be a relatively major retreat from the generalist position, and leaves unexplained why poor readers should make a higher number of semantic false positives than good readers; one would expect the same number and fewer phonetic errors of this type. It seems more parsimonious to conceptualize the two groups of children as adopting different strategies, the poor readers selecting a meaning-based code for storage and good readers equally at home with deep and surface aspects of the words. However, future research may sensibly be directed at disentangling the two theoretical viewpoints.

The possibility that the abnormality just described may underlie difficulties in leaming to read is worth considering because of its import for the design of reading curricula. We suggest that, if there is a causal link in that direction (but see discussion of Experiment 1), it could be because understanding how the alphabet maps into the speech stream demands the separate contemplation of language's sounds. If the first step in that process is inhibitied because of a difficulty in thinking about speech as an object, a child will take that much longer in coming to grips with reading.

Techniques that aid the development of this particular metalinguistic skill would thus be useful in reading programs. There may also be profit in using word-like speech sounds rather than real words in the initial stages.

We have collected some anecdotal evidence that tends to support the contention that some children have trouble thinking about the sounds of words divorced from meaning. In the course of Arnold's (Note 1) thesis work, retarded readers were presented with a variety of elision tasks. One child, when asked to say "highchair" without "chair," answered "low chair." Another offered "half a pencil" when requested to elide the last syllable from "pencil." Finally, in a rather different view, Byrne observed the following incident with his 4-year-old son, Tom. Tom was shown and read the word "Tomato" on a label, and it was pointed out to him that his name was contained within that word. Even though he could read and print his own name, Tom apparently could not comprehend that another word, written or spoken, could contain it as an element. His solution to this self-imposed dilemma was to assert that the word on the label must have said "Tom tomato." Perhaps, if words refer to irreducible things like people and vegetables, children regard the words as equally impenetrable. We suggest that somewhere in the course of reading acquisition the nexus of surface and semantic levels of language needs to be broken.

\section{REFERENCE NOTES}

1. Arnold, L. Word analysis skills in retarded readers. Unpublished BA honors thesis, University of New England, 1975.

2. Andrews, R. J. St. Lucia graded word reading test. Brisbane: Teaching and Testing Resources.

3. Slosson, R. L. Slosson intelligence test. East Aurora, N.Y: Slosson Educational Publications, 1963.

\section{REFERENCES}

Bruce, D. J. The analysis of word sounds by young children. British Journal of Educational Psychology, 1964, 34, 158-170.

EHRI, L. C. Word consciousness in readers and prereaders. Journal of Educational Psychology, 1975, 67, 204-212.

ERdely1, M. H. A new look at the new look: Perceptual defense and vigilance. Psychological Review, 1974, 81, 1-25.

Felzen, E., \& Anisfeld, M. Semantic and phonetic relations in the false recognition of words by third-and sixth-grade children. Developmental Psychology, 1970, 3, 163-168.

FiRTH, I. Components of reading disability. Unpublished doctoral dissertation, University of New South Wales, 1972.

Francis, H. Children's experience of reading and notions of units 
in language. British Journal of Educational Psychology, 1973, 43, 17-23.

Frumkin, B., \& Anisfeld, M. Semantic and surface codes in the memory of deaf children. Cognitive Psychology, 1977, 9, 475-493.

JENKINS, J. J. Remember that old theory of memory? Well, forget it! American Psychologist, 1974, 29, 785-795.

Liberman, I. Y., Shankweiler, D., Fischer, F. W., \& CARTER, B. Reading and the awareness of linguistic segments. Journal of Experimental Child Psychology, 1974, 18, 201-212.

Liberman, I. Y, Shankweiler, D., Liberman, A. M., Fowler, C., \& Fischer, F. W. Phonetic segmentation and recoding in the beginning reader. In $A$. S. Reber \& D. L. Scarborough (Eds.), Toward a psychology of reading: The proceedings of the CUNY conference. New York: Erlbaum, 1977.

Mark, L. S., Shankweiler, D., Liberman, I. Y., \& Fowler, C. A. Phonetic recoding and reading difficulty in beginning readers. Memory \& Cognition, 1977, 5, 623-629.

MCNeil, J. D., \& Stone, J. A note on teaching children to hear separate sounds in spoken words. Journal of Educational Psychology, 1965, 56, 13-15.

Rozin, P., \& Gleitman, L. R. The structure and acquisition of reading II: The reading process and the acquisition of the alphabetic principle. In A. S. Reber \& D. L. Scarborough (Eds.),
Toward a psychology of reading: The proceedings of the CUNY conference. New York: Erlbaum, 1977.

Shankweiler, D., \& Liberman, I. Y. Exploring the relations between reading and speech. In R. M. Knights \& D. J. Bakker (Eds.), The neuropsychology of learning disorders. Baltimore: University Park Press, 1976.

StERn, W. Psychologie der frühen Kindheit. In A. Bar-Adon \& W. F. Leopold (Eds.), Child language: $A$ book of readings. Englewood Cliffs, N.J: Prentice Hall, 1971. (Originally published 1914. Translated by A. Barwell and published as Psychology of early childhood.)

Thonndike, E. L., \& Longe, I. The teacher's word book of 30,000 words. New York: Bureau of Publications, Teachers College, Columbia University, 1944.

Vygotsky, L. S. Thought and language. Cambridge, Mass: M.I.T. Press, 1962.

Williams, J. Building perceptual and cognitive strategies into a reading curriculum. In A. S. Reber \& D. L. Scarborough (Eds.), Toward a psychology of reading: The proceedings of the CUNY conference. New York: Erlbaum, 1977.

(Received for publication February 26, 1979; revision accepted May 16, 1979.) 